\title{
Scalp defects-postaxial polydactyly syndrome
}

INSERM

\section{Source}

INSERM. (1999). Orphanet: an online rare disease and orphan drug data base. Scalp

defects-postaxial polydactyly syndrome. ORPHA:1003

Scalp defects-postaxial polydactyly syndrome is characterised by congenital scalp defects and postaxial polydactyly type A. 